\title{
Bariatric surgery in Azerbaijan: A single center experience
}

\author{
Taryel Omarov, ${ }^{1}$ Aygun Ibrahimova, ${ }^{1}$ Aslan Abdullayev, ${ }^{1}$ \\ Nuru Bayramov, ${ }^{1}$ Tevfik Tolga Şahin, ${ }^{2}$ \\ 'Department of Surgical Diseases-l; Azerbaijan Medical University, Bakü, Azerbaijan \\ ${ }^{2}$ Department of Surgery and Turgut Ozal Medical Center Institute of Liver Transplantation, İnönü University Faculty of Medicine, \\ Malatya, Turkey
}

\begin{abstract}
Introduction: The aim of this study was to investigate the outcomes of bariatric surgery in cases of morbid obesity.

Materials and Methods: An analysis of the results of 88 patients with morbid obesity [average age $40 \pm 19$ years; average body mass index (BMI) $59.95 \pm 20.25 \mathrm{~kg} / \mathrm{m} 2$ ] who underwent bariatric surgery was conducted. Patient demographics, operative technique, associated diseases, and follow-up results at postoperative 1 , 3,6 , and 12 months were examined.
\end{abstract}

Results: A total of 78 (88.6\%) patients who underwent laparoscopic sleeve gastrectomy (LSG) achieved a mean weight loss of $39.5 \pm 11.5 \mathrm{~kg}$ in the first 6 months. In 10 (11.4\%) patients who underwent gastric bypass surgery, the mean weight loss was $46 \pm 14 \mathrm{~kg}$ in the first 6 months. During the second 6 months, the total weight loss in LSG patients was $33.5 \pm 8.5 \mathrm{~kg}$.

Conclusion: Following a thorough evaluation of patients with morbid obesity, a patient-oriented operation can yield excellent results. LSG and gastric bypass are 2 surgical modalities that can be applicable and effective in patients with morbid obesity. Bariatric surgery has also recently been performed at this center, and although new, our results seem comparable with the literature.

Keywords: Gastric bypass; morbid obesity; sleeve gastrectomy.

\section{Introduction}

Obesity is a chronic, multi-systemic disease which reduces the quality of life of and reduces the overall life span of the affected individual. Obesity has severe implications on the individual causing type 2 diabetes mellitus, hypercoagulability and reduced venous return causing a tendency to deep venous thrombosis, fatty liver disease, infertility and sexual dysfunction. ${ }^{[1]}$ Furthermore, there is increased risk of development of osteoarthritis and cancer in various organ systems such as colon, breast and liver. The incidence obesity is increasing in both developed and developing countries. ${ }^{[2]}$

The surgical treatment of obesity found worldwide acceptance in general surgical practice. Although there are wide variety of techniques that are applied only few found worldwide acceptance. ${ }^{[3]}$ Historical information on 
such operations date back in 1950s, more efficient surgical procedures have begun to be formed since 1979. ${ }^{[4]}$ In 1992 World Health Organization accepted the role of the bariatric surgery in the treatment of severe and refractory obesity for the first time and ever since there has been a great deal of development on this area. Conservative management of obesity including, life style changes and medical therapy, has low success rate and high treatment failure with weight regain. Selection of the best type of operation should be individualized depending on condition of the patient, severity of the disease and comorbidities that are present. ${ }^{[5]}$ Body mass index (BMI) is widely used to assess the severity of obesity and usually individual with a $\mathrm{BMI}<35 \mathrm{~kg} / \mathrm{m}^{2}$ are treated conservatively. ${ }^{[6]}$

Fundamental concept of bariatric surgery the most efficient treatment of obesity, is to reduce appetite and/ or food absorption from gastrointestinal system and resolution of the comorbidities associated with obesity during the process. Therefore, although there are wide variety of bariatric procedures that are applied, they are technically divided in to restrictive, malabsorbtive and combined operations. Restrictive procedures such as laparoscopic sleeve gastrectomy (LSG) or adjustable gastric banding intend to reduce the food intake thus aim to restrict the caloric intake of the patients. Malabsorbtive procedures such as ileojejunal bypasses aim changing the gastrointestinal continuity and thus resulting in the disrupted absorption of the nutrients. However pure malabsorbtive procedures are not used in the current bariatric surgical practice due to high complication rates. Combined procedures use both restriction and malabsorption cause weight loss and currently all bypass types and biliopancreatic diversions fall in to this category. ${ }^{[7]}$

Although restriction of the caloric intake is the main mechanism of action of bariatric procedures there are many humoral mechanisms that result in endocrine mechanisms that has impact on the glucose and lipid homeostasis of the individual. This results in resolution of the concomitant diseases such as diabetes, hyperlipidemia and hypertension. ${ }^{[8]}$

We prefer and most frequently apply LSG in our center. The aim of the present study was to investigate outcomes of open and laparoscopic bariatric surgery in morbidly obese patients operated in our center.

\section{Materials and Methods}

\section{Study Design and Inclusion of the Patients}

In the present study; 88 patients with morbid obesity who have undergone bariatric surgery in the Modern Hospital and Educational Surgical Clinic of Azerbaijan Medical University between 2013 and 2016, have been included in the study for evaluation. Postoperative complications and resolution of the associated diseases were investigated.

\section{The Patient Selection and Evaluation}

The indications for operation, patient selection and evaluation are performed according to the international guidelines established by the EASO and IFSO-EC joint committee in 2013 (European Association for the study of Obesity and International Federation for Surgery of Obesity-The European Chapter).$^{[9]}$ Briefly; pre-operative weights, body mass index (BMI) and comorbidities of patients were recorded. During the preoperative period, all patients were assessed by gastroscopy for examining upper gastrointestinal system, and by ultrasonography for examining liver, biliary tract pathology. As part of preparation for surgery, all patients passed consultations of pulmonologist, cardiologist, dietician, psychologist and endocrinologist, and anesthetic risk assessment. Before and after operation low molecular heparin was applied for pulmonary thromboembolism prophylaxis. Furthermore, external passive compression stockings were used before operation, and intraoperative dynamic external compression devices were used intraoperatively. Prophylactic antibiotic was applied as a single dose before operation and two doses afterwards. Postoperative complications and resolution of the associated diseases were investigated by a regular follow up of the patients. Patient BMI, weight loss was evaluated on postoperative $1^{\text {st }}, 3^{\text {rd }}, 6^{\text {th }}$ and $12^{\text {th }}$ months. All patients were treated with proton pump inhibitor, acid neutralizers and dietary procedures during the first postoperative 90 days. Patients who had gastric bypass surgery were subject to blood tests once a month, and if needed, received parenteral vitamin-mineral supplement.

\section{The Type of Operations Performed}

Operation techniques in all groups complied with international standards. Roux-en-Y gastric (RYGB) bypass and minigastric (MGB) bypass were performed according to the standard technique that has been described elsewhere by other researchers. ${ }^{[10,11]}$ However, LSG was performed ac- 
Table 1. Summary of the associated diseases among the patients in the study. The values are expressed as number of patients (percentage) [n (\%)]

\begin{tabular}{lcc} 
The type of associated disease & \multicolumn{2}{c}{ Value } \\
\cline { 2 - 3 } & $\mathbf{n}$ & $\%$ \\
\hline Type 2 diabetes mellitus & 34 & 38.6 \\
Hypertension & 23 & 26.1 \\
Obstructive sleep apnea syndrome & 9 & 10.2 \\
Polycystic ovarian syndrome in women & 12 & 13.6 \\
Loss of libido in men & 5 & 5.6 \\
Degenerative osteoarthritis & 14 & 15.9 \\
Chronic obstructive lung disease & 1 & 1.1 \\
Coronary artery disease & 2 & 2.2 \\
Fatty liver disease & 86 & 98 \\
\hline
\end{tabular}

cording to our modified technique. Briefly; we complete resection by $32 \mathrm{Fr}$ calibrating tube and $60 \mathrm{~mm}$ lined staple towards fundus in parallel with minor curve after $2 \mathrm{~cm}$ distance from pylorus. We create smaller stomach because of these two methods, and achieve more noticeable and long-term weight loss. In the next stage, methylene blue is injected into stomach, and staple line is controlled. In order to minimize perioperative bleeding and anastomosis leak risk, staple line is sutured (with omentopexy in necessary cases). Omentopexy is performed for controlling further gastric torsion and possible leaks from staple line. Drainage is applied to all patients for preventive control of possible staple line leaks. The operation ends with the removal of resected stomach from $15 \mathrm{~mm}$ trocar incision.

\section{Statistical Analysis}

We performed descriptive statistical analysis. The contin- uous data are expressed as mean and standard deviation. The nominal data are expressed in percentage when necessary together with the number of subjects.

\section{Results}

\section{Demographic Data of the Patients}

There were 88 patients with morbid obesity that underwent bariatric surgery in our center. Average age was $40 \pm 19$ years. Average BMI was $59.95 \pm 20.25 \mathrm{~kg} / \mathrm{m}^{2}$ in the study. Of the eighty-eight patients $76(86.3 \%)$ were females and $12(13.6 \%)$ were males. The obesity associated diseases are summarized in Table 1. The two patients with coronary artery disease had received a coronary stenting before the bariatric operation and had a good coronary performance as stated by the cardiologist. The allocation of the patients according to the type of the operation is summarized in the flowchart in Figure 1. Surgical operations were open in two (2.2\%) patients, and laparoscopic in remaining (97.7\%) patients. Average duration of operation was $2.5 \pm 0.5$ hours and average duration of hospital stay was $2.5 \pm 0.5$ days.

\section{Postoperative Follow Up}

There were no mortalities observed. One (1.1\%) patient undergone re-operation due to anastomosis leak four days after operation, one (1.1\%) patient experiences hypotension the day after operation and treated supportive therapy including fluids and sympathomimetic drugs. Symptoms of dysphagia were observed in one patient $(1.1 \%)$ three days after operation, and one in one patient (1.1\%) month after operation. There was no mechanical tightness in the endoscopic evaluation and the patients

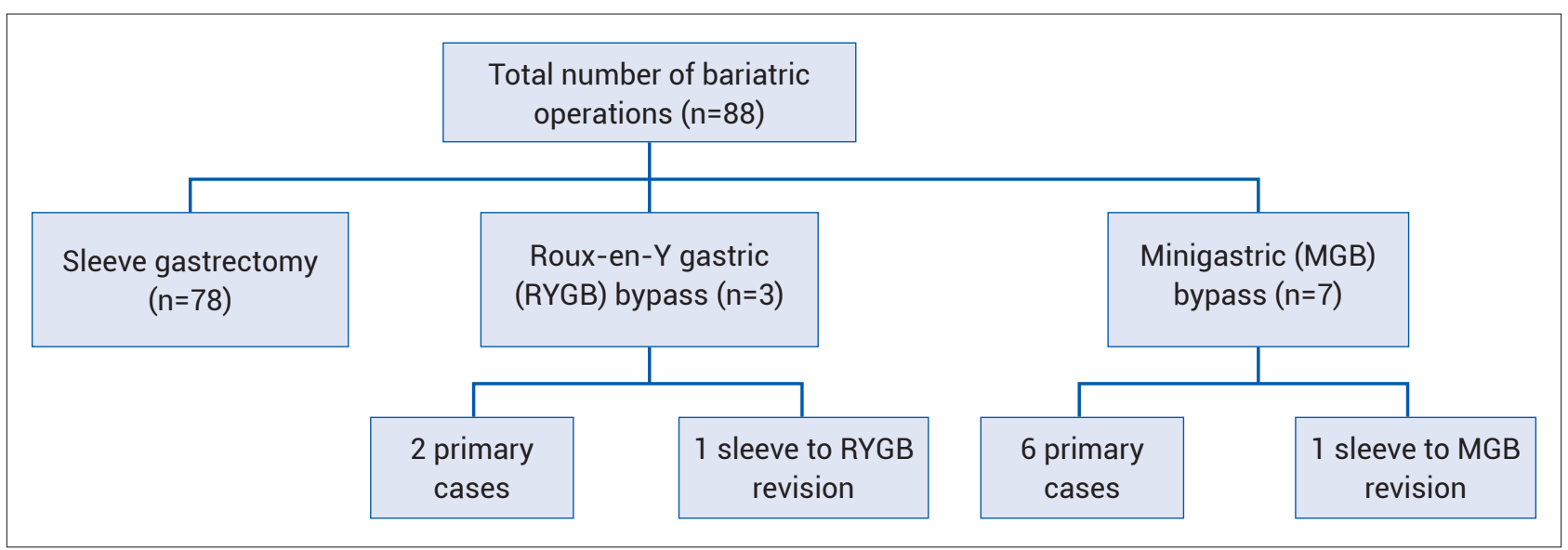

Figure 1. The allocation of the patients to the operation groups. RYGB: Roux-en-Y gastric bypass; MGB: Minigastric bypass. 
Table 2. Excess weight loss of the patients according to different surgical procedures

\begin{tabular}{|c|c|c|}
\hline & EWL first 6 months (kg) & Second 6 months (kg) \\
\hline & Mean $\pm S D$ & Mean $\pm S D$ \\
\hline Laparoscopic sleeve gastrectomy & $39.5 \pm 11.5$ & $22.5 \pm 4.5$ \\
\hline Modified laparoscopic sleeve gastrectomy & $44 \pm 13$ & $28.5 \pm 6.5$ \\
\hline Laparoscopic Roux-en-Y gastric bypass & $46 \pm 14$ & $33.5 \pm 8.5$ \\
\hline
\end{tabular}

were treated with conservative management. The symptoms were normalized after three months without any need for intervention. Eleven (12.5\%) patients undergone abdominoplasty 14 months after operation in order to restore normal appearance.

In 22 patients out of 23 patients with hypertension resolved after the operation but, in one patient no improvement was observed. In 9 patients out of 12 (13.6\%) suffering from hypertension, fatty liver disease and hyperlipidemia resolved in the first three months after operation. Thirtyone of the 34 (94.2\%) patients with type 2 diabetes mellitus the normo-glycemic state was achieved in the first three months. However, in remaining two patients (5.8\%) dysregulated HbA1c and C-peptide levels persisted for three months and were normalized in the following periods. In another patient (2.9\%) need for combined antidiabetic drug was reduced to a single dose and was continued there on. In the male patients, deficiency of free plasma testosterone levels and sex hormone-binding globulin levels was identified (Data not shown). These patients demonstrated improvement during six-month control, and by the end of the twelfth month normal ranges were obtained, except one patient.

\section{Postoperative Complications}

Anastomosis leak from fundal part was observed in one (1.1\%) patient five days after LSG. Patient was immediately hospitalized and undergone intensive treatment, as well as percutaneous drainage of sub-hepatic and left sub-diaphragmatic areas. On the next day, fully covered bariatric stent was placed, and the patient was discharged after three days under strict ambulatory control. Following the 5-week of control period, the stent was removed, and no leakage was observed in subsequent period. Gastroesophageal reflux was observed in 11 (12.5\%) patients two months after operation, dumping syndrome in one
(1.1\%) patient, who undergone LSG, and diarrhea 5-6 times a day in one (1.1\%) patient, who undergone MGB.

\section{Postoperative Weight Loss}

During the first 6 months, the patients, who undergone standard LSG, achieved weight loss of $39.5 \pm 11.5 \mathrm{~kg}$. weight loss was $44 \pm 13 \mathrm{~kg}$ in patients for whom smaller stomach was formed. However, in patients who undergone standard LSG, weight loss index decreased in the second 6 months compared to the first 6 months, and equaled to $22.5 \pm 4.5 \mathrm{~kg}$. In our modified LSG technique with a smaller gastric remnant the weight loss in the second six months was $28.5 \pm 6.5 \mathrm{~kg}$. Excess body weight loss rate after LSG was found to be $42.6 \%$ among our patients. When questioning one patient who lost relatively less weight, we identified regular intake of liquefied chocolate, beer and similar high-calorie drinks during the hunger crisis. This patient returned to normal state after special diet.

Weight loss was $46 \pm 14 \mathrm{~kg}$ in the first six months in patients who undergone gastric bypass surgery, and during the second 6 months it was observed equaling to $33.5 \pm 8.5$ $\mathrm{kg}$ (Table 2).

\section{Discussion}

LSG is relatively new surgical method. Average stomach size is reduced by $100-120 \mathrm{ml}$. Though the key weigh loss mechanism of the operation is the reduction of stomach size. Furthermore, ghrelin hormone produced from gastric fundus is not produced after operation, which plays an important role in weight loss and solving metabolic disorders. During the operation, after the gastric fundus is resected along the major curve by the straight line up to gastro-esophageal junction, this hormone cannot be secreted, which strongly reduces the desire to eat, and consequently, leads to efficient and sustained weight loss. Currently, LSG is the most common type of surgery. ${ }^{[12,13]}$ 
In RYGB, stomach is resected by proximal staple and pouch of approximately $20 \mathrm{~mm}$ is formed. Jejunum is resected at $40-50 \mathrm{~cm}$ distal from ligament of Treitz and connected to stomach pouch with $1 \mathrm{~cm}$ anastomosis. Proximal part of small intestine is anastomosed to $75-150 \mathrm{~cm}$ distal part depending on obesity level of patient. ${ }^{[14-16]}$ In MGB or one anastomosis gastric bypass, stomach is resected with proximal staple in parallel with minor curve, and pouch of approximately $60-80 \mathrm{~mm}$ is formed. Jejunal loop is lifted at $200-250 \mathrm{~cm}$ distal from ligament of Treitz and connected to stomach pouch with $1 \mathrm{~cm}$ anastomosis. ${ }^{[17]}$ Abou Ghazaleh et al. ${ }^{[18]}$ have reported that MGB and RYGB was superior in controlling diabetes and as well as the incretin effect when compared to restrictive procedures such as LSG. Furthermore, they have concluded that MGB in terms technique applicability and the results have been comparable or superior to RYGB. ${ }^{[18]}$ Our experience with the gastric bypass surgery is yet evolving but it seems that our results and complication rates are within the range that is reported in the literature. However, our patient number is not enough to draw any conclusions.

Post-LSG gastroesophageal reflux is worth to be discussed. This issue is caused by loss of gastroesophageal junction during the operation and fast eating without following postoperative diet. We observed this pathology in $11(12.5 \%)$ patients during our study. Some publications of world literature indicated this range as $3-21 \%{ }^{[19,20]}$ Our gastroesophageal reflux rate seems reasonable when compared with the reported results.

One of the issues reducing the success rate of treatment in obese patients is eating behavior and patient compliance. Publications investigating the relation between the obesity and neural circuits report that there is connection between pleasure and reward circuits and success of the operation. ${ }^{[21,22]}$ Although the obesity is not considered as surgical problem, it will be difficult to achieve expected weight loss unless the patients change their old habits of being happy by eating, joy of secret eating and eating too much. Despite that concepts of successful and unsuccessful bariatric procedure have been recognized until recently, many researchers consider $15-50 \%$ weight loss resulting from this procedure as successful. ${ }^{[12]}$ In our series it is $42.6 \%$ and it seems generally that our procedures are successful.

\section{Conclusion}

Despite the promising results in short and medium term, long-term results are not sufficient for this method. Unlike other methods, few cases of vitamin deficiency and malabsorption, as well as efficient weight loss ratio after LSG enable wide application of this method. Consequently, LSG is believed to be a reliable method, which ensures sufficient weight loss in the treatment of obesity and super-obesity, as well as improvement in comorbidities.

\section{Disclosures}

Ethichs Committee Approval: All procedures performed in studies involving human participants were in accordance with the ethical standards of the institutional and/ or national research committee and with the 1964 Helsinki declaration and its later amendments or comparable ethical standards.

Informed Consent Statement: Informed consent was obtained from all individual participants included in the study.

Peer-review: Externally peer-reviewed.

Conflict of Interest: None declared.

\section{References}

1. Fobi MA. Surgical treatment of obesity: a review. J Natl Med Assoc 2004;96:61-75.

2. Buchwald H, Oien DM. Metabolic/bariatric surgery worldwide 2011. Obes Surg 2013;23:427-36. [CrossRef]

3. Buchwald $\mathrm{H}$. The evolution of metabolic/bariatric surgery. Obes Surg 2014;24:1126-35. [CrossRef]

4. Eldar S, Heneghan HM, Brethauer SA, Schauer PR. Bariatric surgery for treatment of obesity. Int J Obes (Lond) 2011;35 Suppl 3:S16-21. [CrossRef]

5. Gastrointestinal surgery for severe obesity: National Institutes of Health Consensus Development Conference Statement. Am J Clin Nutr 1992;55:615S-9S. [CrossRef]

6. Karmali S, Schauer P, Birch D, Sharma AM, Sherman V. Laparoscopic sleeve gastrectomy: an innovative new tool in the battle against the obesity epidemic in Canada. Can J Surg 2010;53:126-32.

7. Mechanick JI, Youdim A, Jones DB, Garvey WT, Hurley DL, McMahon MM, et al. Clinical practice guidelines for the perioperative nutritional, metabolic, and nonsurgical support of the bariatric surgery patient--2013 update: cosponsored by American Association of Clinical Endocrinologists, The Obesity Society, and American Society for Metabolic \& Bariatric Surgery. Obesity (Silver Spring) 2013;21 Suppl 1:S1-27.

8. Cetinkunar S, Erdem H, Aktimur R, Sozen S. Effect of bariatric surgery on humoral control of metabolic derangements in obese patients with type 2 diabetes mellitus: How it works. World J Clin Cases 2015;3:504-9. [CrossRef]

9. Fried M, Yumuk V, Oppert JM, Scopinaro N, Torres AJ, Weiner $\mathrm{R}$, et al. Interdisciplinary European Guidelines on metabolic 
and bariatric surgery. Obes Facts 2013;6:449-68. [CrossRef]

10. Rutledge R, Walsh TR. Continued excellent results with the mini-gastric bypass: six-year study in 2,410 patients. Obes Surg 2005;15:1304-8. [CrossRef]

11. Vines L, Schiesser M. Gastric bypass: current results and different techniques. Dig Surg 2014;31:33-9. [CrossRef]

12. Gagner M, Hutchinson $C$, Rosenthal R. Fifth International Consensus Conference: current status of sleeve gastrectomy. Surg Obes Relat Dis 2016;12:750-6. [CrossRef]

13. Benaiges D, Goday A, Pedro-Botet J, Más A, Chillarón JJ, Flores-Le Roux JA. Bariatric surgery: to whom and when? Minerva Endocrinol 2015;40:119-28.

14. Scopinaro N, Gianetta E, Civalleri D, Bonalumi U, Bachi V. Bilio-pancreatic bypass for obesity: II. Initial experience in man. Br J Surg 1979;66:618-20. [CrossRef]

15. Scozzari G, Passera R, Benvenga R, Toppino M, Morino M. Age as a long-term prognostic factor in bariatric surgery. Ann Surg 2012;256:724-8. [CrossRef]

16. Terra X, Auguet T, Guiu-Jurado E, Berlanga A, OrellanaGavaldà JM, Hernández $M$, et al. Long-term changes in leptin, chemerin and ghrelin levels following different bariatric surgery procedures: Roux-en $-Y$ gastric bypass and sleeve gastrectomy. Obes Surg 2013;23:1790-8. [CrossRef]

17. Kular KS, Manchanda N, Rutledge R. A 6-year experience with 1,054 mini-gastric bypasses-first study from Indian subcontinent. Obes Surg 2014;24:1430-5. [CrossRef]

18. Abou Ghazaleh R, Bruzzi M, Bertrand K, M'harzi L, Zinzindohoue F, Douard R, et al. Is Mini-Gastric Bypass a Rational Approach for Type-2 Diabetes? Curr Atheroscler Rep 2017; 19:51. [CrossRef]

19. Sarkhosh K, Birch DW, Sharma A, Karmali S. Complications associated with laparoscopic sleeve gastrectomy for morbid obesity: a surgeon's guide. Can J Surg 2013;56:347-52.

20. Stenard F, lannelli A. Laparoscopic sleeve gastrectomy and gastroesophageal reflux. World J Gastroenterol 2015;21:10348-57. [CrossRef]

21. Larjani S, Spivak I, Hao Guo M, Aliarzadeh B, Wang W, Robinson $\mathrm{S}$, et al. Preoperative predictors of adherence to multidisciplinary follow-up care postbariatric surgery. Surg Obes Relat Dis 2016;12:350-6. [CrossRef]

22. Holsen LM, Davidson P, Cerit H, Hye T, Moondra P, Haimovici F, et al. Neural predictors of 12-month weight loss outcomes following bariatric surgery. Int J Obes (Lond) 2017 Aug 14, [Epub ahead of print] doi: 10.1038/ijo.2017.190. [CrossRef] 